\title{
Recognition and environmental context: The effect of testing by phone
}

\author{
JOSE J. CANAS and DOUGLAS L. NELSON \\ University of South Florida, Tampa, Florida
}

\begin{abstract}
Many experiments have shown that recognition memory is relatively unaffected by changes in environmental testing context. In the experiment reported in this paper, subjects studied a list of words in the laboratory and were tested by surprise by phone when they were at home. The results showed a significant impairment in recognition, relative to recognition by controls tested in the laboratory. This context effect seems to be related to the difficulty that subjects experienced in mentally reinstating the study context.
\end{abstract}

A number of experiments have shown that recall is impaired when subjects are tested in a physical location different from that in which they studied the material. However, these studies also reported that recognition memory is essentially unaffected by changes in the environmental testing context (Godden \& Baddeley, 1975; Smith, Glenberg, \& Bjork, 1978). These results are consistent with several generation-recognition theories of memory. For example, Anderson and Bower (1972), Bahrick (1970), and Kintsch (1970) have interpreted this result as evidence favoring the hypothesis that the environment acts primarily as a generation cue. Unlike recall, recognition does not involve a generation stage, and therefore, changes in the environmental context should have no effect on recognition performance.

Although the absence of context effects in recognition has consistently been found (e.g., Fernandez \& Glenberg, 1985; Smith et al., 1978), most experiments have involved one of two types of environmental change: (1) A change of physical context is made within the same experimental environment. For example, subjects are tested in a room different from the room in which they studied the material. However, both rooms are in the same building (usually the psychology building), and the subjects know that they are in the same experiment with the same experimenter present. (2) A drastic change is made in the physical context. For example, Godden and Baddeley (1975) had subjects study on land and then tested them underwater, and the reverse. Subjects knew that they were going to be tested, and they also helped the experimenter set up the test environment.

Note that both changes require the subject to stay in what may be called the "experimental mood." At test, subjects know that they still are in the experiment. Fernandez and Glenberg (1985) suggested that, from the point

This research was supported by Grant No. MH 16360 from the National Institute of Mental Health to Douglas L. Nelson. The authors are indebted to Carolyn Best for her help in collecting the data and especially to Maria Teresa Bajo for her comments and ideas.

Requests for reprints should be sent to Douglas L. Nelson, Department of Psychology, University of South Florida, Tampa, FL 33620. of view of the subject, the test takes place within the context of an experiment and this feature does not change with changes in physical location. Accordingly, it should be easy for the subject to reinstate the study context mentally, which would eliminate possible context effects. Smith (1979) showed that the context effect on recall disappeared when the subjects were instructed to remember their study environment prior to being tested.

The purpose of the present experiment was to explore another way of changing context to determine its effects on recognition memory. Subjects were tested in a completely different but familiar context, one in which they would never expect to be tested. Subjects studied a list of words in a room in the laboratory, and then were tested at home by phone. In these circumstances, subjects were expected to have a more difficult time reinstating the experimental environment in which the list of words had been studied, and to the extent that this was the case, context effects in recognition should emerge.

Two control groups were used. In both groups, subjects were tested in the same room in which they studied the words, but the groups differed in terms of the modality of the test. In one group, each test word was presented on the screen as at study, and in the second group, the experimenter read each test word aloud. Comparisons between these two lab-tested groups were used to evaluate the effect of changing modality from study to test. The comparison between the auditory lab condition and the phone condition was expected to show the effect of changing the test context.

\section{METHOD}

\section{Subjects}

The subjects were 36 University of South Florida students enrolled in introductory psychology courses. They received course credit for participation. Twelve subjects were assigned to each of the three test context conditions.

\section{Materials}

A total of 200 words were used in the experiment. Of these, 100 words were used to construct the study list and 100 words were used as distractors in the recognition test. The target words were selected from 
controlled association norms (Nelson \& McEvoy, 1979), which were obtained by asking large groups of subjects to write the first word that came to mind that was meaningfully associated to the presented word. Category size was estimated by counting the total number of different responses given by 2 or more subjects. Fifty of the selected targets defined a large category size (mean $=19.2, S D=3.29$ ) and 50 defined a small category size (mean $=6.46, S D=1.62$ ). Mean frequency of usage was $39.56(S D=30.35)$ and $42.52(S D=30.91)$ for small and large category size words, respectively. The distractors were selected so that their frequency of occurrence matched that of the targets. Although category size has no effect on recognition under the conditions used here (Nelson, Canas, Casanueva, \& Castano, 1985), it was manipulated in this experiment to explore the possibility that it might interact with changes in testing context. However, this interaction was not present. Category size had no effect on and did not interact with any other variable, and, except for presenting the means, it will not be considered any further.

\section{Procedure}

Each subject participated individually in a single study-test session. The study session was equal for all subjects and took place in a small laboratory room on the university campus. Subjects were told that they were going to see a long list of words and they were to attempt to remember as many of the words as they could. The experimenter then presented 100 words, 1 at a time, on the screen using a Kodak carousel projector at a rate of $3 \mathrm{sec}$ per word. Immediately after the study word, subjects received further instructions that depended on the test condition.

Phone condition. The experimenter indicated that she was having some problems with the equipment and could not run the second part of the experiment that day. She asked the subject for his or her phone number and a time when he/she could be reached so the experimenter could call to set up another appointment. The experimenter emphasized that it was very important that they finish the experiment within $48 \mathrm{~h}$. The next day, approximately $24 \mathrm{~h}$ (mean elapsed time for this condition was $26 \mathrm{~h}, 1 \mathrm{~min} ; S D=1 \mathrm{~h}, 56 \mathrm{~min}$ ) after the study session, the experimenter called each subject. She identified herself and indicated that they could do the second part of the experiment over the phone. The experimenter then proceeded to read each of the 100 study and 100 distractor words, which were randomly intermixed. The subject responded "yes" or "no" to each word, depending on whether he/she remembered seeing the word the day before. At the completion of testing, the experimenter started a short conversation with the subject to determine what the subject was doing and where he/she was living. Three subjects lived in university dormitories, 6 in apartments, and 3 with their parents. When talking to 1 dormitory subject and 2 apartment subjects, the experimenter heard a low level of background noise from a television, but the conversation was not interrupted. All subjects said that they were doing nothing in particular when the experimenter called, with the exception of one subject who said she was cooking.

Laboratory conditions. In the oral and visual test conditions, each subject was also told that were was a problem with the equipment so that the second part of the experiemnt could not be completed that day. Therefore, a time for the next day was set to finish it. The experimenter set the time for approximately $24 \mathrm{~h}$ later. The means of elapsed time for each condition were $24 \mathrm{~h}, 33 \mathrm{~min}$ for the auditory test condition ( $S D$ $=1 \mathrm{~h}, 38 \mathrm{~min})$ and $24 \mathrm{~h}, 4 \mathrm{~min}$ for the visual test condition $(S D=$ $1 \mathrm{~h}, 33 \mathrm{~min}$ ). When he/she returned, the subject was told that he/she had to remember the words that were studied the day before. In the visual test condition, each of 200 words was presented on the same screen that was used to present the study list. The subject responded "yes" or "no" depending on whether he/she remembered seeing the word the day before. In the oral test condition, the experimenter read each word and the subject responded the same way.

\section{RESULTS}

Table 1 shows mean probability of hits, false alarms, and corrected recognition scores (hits minus false alarms divided by 1 minus false alarms) as a function of the ex-
Table 1

Probabilities of Hits, False Alarms, and Corrected Recognition as a Function of Category Size and Testing Condition

\begin{tabular}{|c|c|c|c|c|}
\hline \multirow{2}{*}{$\begin{array}{c}\text { Test } \\
\text { Condition } \\
\end{array}$} & \multirow[b]{2}{*}{ Response Category } & \multicolumn{2}{|c|}{ Category Size } & \multirow[b]{2}{*}{ Mean } \\
\hline & & Small & Large & \\
\hline \multirow[t]{3}{*}{ Visual } & Hits & .65 & .67 & \\
\hline & False Alarms & .35 & .26 & \\
\hline & Corrected Recognition & .46 & .45 & .46 \\
\hline \multirow[t]{3}{*}{ Oral } & Hits & .57 & .61 & \\
\hline & False Alarms & .28 & .26 & \\
\hline & Corrected Recognition & .40 & .47 & .44 \\
\hline \multirow[t]{3}{*}{ Phone } & Hits & .47 & .53 & \\
\hline & False Alarms & .26 & .28 & \\
\hline & Corrected Recognition & .28 & .35 & .31 \\
\hline
\end{tabular}

perimental conditions. An analysis of variance on the corrected scores showed that only test condition was significant $[F(2,33)=4.86, M S e=.015, p<.05]$.

Fisher's least significant difference (LSD) was .09, indicating that the differences between the phone condition and the oral condition and between the phone condition and the visual condition were both significant. In other words, subjects in the phone condition showed lower recognition levels than subjects in either of the laboratory conditions, whose levels did not differ from each other.

\section{DISCUSSION}

The results showed an impairment in recognition performance equal to about $1 S D$ when subjects were tested at home. This effect was not due to testing subjects on a different modality from the one used to present the study list. The similar levels of performance in the visual and oral test conditions ruled out this possibility. These results are consistent with the hypothesis that subjects in the phone condition were less able to mentally reinstate the study context. Subjects in this condition were at home, watching TV or cooking, mentally far away from any psychological experiment. They knew that they had to remember the list of words that they had studied, but they were not expecting the test at that time and over the phone. Their recognition scores were not as good as those of the subjects that sat in the experimental room ready to continue with the experiment that had been interrupted the day before. This finding suggests that previous failures to find contextual effects in recognition (Fernandez \& Glenberg, 1985; Smith et al., 1978) may be due to failure to effectively manipulate the subjects' ability to mentally reinstate the study context. As suggested by Fernandez and Glenberg, the critical feature for the subject is that the events take place within the context of an experiment and, although changing rooms in the lab does not appear to change that context, changing from the lab to the home environment appears to significantly alter that context.

Finally, the present findings lead us to question the general interpretation that generation-recognition models offer for the lack of context effects in recognition (Anderson \& Bower, 1972; Bahrick, 1970; Kintsch, 1970). These models assume that subjects associate the study words with the environmental context in which they were presented. In recall testing, subjects use the context as a cue to generate potential targets and, when the target is produced, it can be recognized. In recognition testing, however, the target does not need to be generated since it is already present. Therefore, contextual changes should impair recall by reducing the likelihood of successful generation and should have no effect on recognition since there is no need for a generation phase. Therfore, there should be no context effect. However, the context effect found in this experiment is inconsistent with these models. 


\section{REFERENCES}

ANDERSON, J. R., \& Bower, G. H. (1972). Recognition and retrieval processes in free recall. Psychological Review, 79, 97-123.

BaHrick, H. P. (1970). Two-phase model for prompted recall. Psychological Review, 77, 215-222.

Fernandez, A., \& GlenberG, A. M. (1985). Changing environmental context does not reliably affect memory. Memory \& Cognition, 13, 333-345.

GodDEN, D. R., \& BADDELeY, A. D. (1975). Context-dependent memory in two natural environments: On land and underwater. British Journal of Psychology, 66, 325-331.

KINTSCH, W. (1970). Learning, memory and conceptual process. New York: Wiley.
Nelson, D. L., Canas, J. J., Casanueva, D. M., \& Castano, D. (1985). Prior knowledge and recognition. American Journal of Psychology, 98, 379-397.

Nelson, D. L., \& McEvoy, C. L. (1979). Encoding context and set size. Journal of Experimental Psychology: Human Learning \& Memory, 5, 292-314.

SMITH, S. M. (1979). Remembering in and out of context. Journal of Experimental Psychology: Human Learning \& Memory, 5, 460-471.

SMith, S. M., Glenberg, A., \& BJoRK, R. A. (1978). Environmental context and human memory. Memory \& Cognition, 6, 342-353.

(Manuscript received for publication May 27, 1986.) 